\title{
Parents' and teachers' perspectives on changes in childcare quality in the United States, Russia and Finland
}

\begin{tabular}{|c|c|}
\hline \multicolumn{2}{|c|}{$\begin{array}{l}\text { Authors: } \\
\text { Eeva Hujala }{ }^{1} \\
\text { Janniina Vlasov }^{2} \\
\text { Tünde Szecsi }\end{array}$} \\
\hline \multicolumn{2}{|c|}{$\begin{array}{l}\text { Affiliations: } \\
{ }^{1} \text { Department of Early } \\
\text { Childhood Education, } \\
\text { University of South Africa, } \\
\text { South Africa }\end{array}$} \\
\hline \multicolumn{2}{|c|}{$\begin{array}{l}{ }^{2} \text { Faculty of Education, } \\
\text { University of Tampere, } \\
\text { Finland }\end{array}$} \\
\hline \multicolumn{2}{|c|}{$\begin{array}{l}{ }^{3} \text { Department of Teacher } \\
\text { Education, Florida Gulf Coast } \\
\text { University, United States }\end{array}$} \\
\hline \multicolumn{2}{|c|}{$\begin{array}{l}\text { Corresponding author: } \\
\text { Eeva Hujala, } \\
\text { eeva.hujala@gmail.com }\end{array}$} \\
\hline \multicolumn{2}{|c|}{$\begin{array}{l}\text { Dates: } \\
\text { Received: } 03 \text { May } 2017 \\
\text { Accepted: } 30 \text { Aug. } 2017 \\
\text { Published: } 14 \text { Nov. } 2017\end{array}$} \\
\hline \multicolumn{2}{|c|}{$\begin{array}{l}\text { How to cite this article: } \\
\text { Hujala, E., Vlasov, J. \& Szecsi, } \\
\text { T., 2017, 'Parents' and } \\
\text { teachers' perspectives on } \\
\text { changes in childcare quality } \\
\text { in the United States, Russia } \\
\text { and Finland', South African } \\
\text { Journal of Childhood } \\
\text { Education 7(1), a538. https:// } \\
\text { doi.org/10.4102/sajce. } \\
\text { v7i1.538 }\end{array}$} \\
\hline \multicolumn{2}{|c|}{$\begin{array}{l}\text { Copyright: } \\
\text { (C) 2017. The Authors } \\
\text { Licensee: AOSIS. This } \\
\text { is licensed under the } \\
\text { Creative Commons } \\
\text { Attribution License. }\end{array}$} \\
\hline \multicolumn{2}{|l|}{ Read online: } \\
\hline 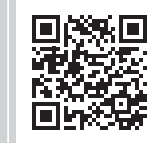 & $\begin{array}{l}\text { Scan this QR } \\
\text { code with your } \\
\text { smart phone or } \\
\text { mobile device } \\
\text { to read online. }\end{array}$ \\
\hline
\end{tabular}

This article reports on the findings of a follow-up study, which examined parents' and teachers' perspectives regarding the quality of childcare for 3- to 5-year-old children in the United States, Russia and Finland between 1991 and 2011. The study aims to address a gap in early childhood education (ECE) research by examining how the quality of ECE has changed in international settings over the past decades, thus expanding comprehension of the diversity within the ECE phenomena and its culture-specific nature. With a focus on the quality of ECE, this study examines the parents' and teachers' perspectives on key elements of the implementation of ECE in childcare centres: programme structure, curriculum goals, the role of parents and teachers as partners in children's lives, as well as children's satisfaction with their childcare. The results indicate that there have been differences in ECE quality between the studied societies both in structural aspects as well as in process and effect factors in all data collection cohorts. It seems that ECE quality and the changes within it may be connected to ECE policy based on the societal values. The results suggest that to understand ECE and its pedagogy, one has to be aware of the value-laden cultural contexts in a society.

\section{Introduction}

Quality early childhood education (ECE) services have risen to the top of the political agendas in many countries (Moss 2012). Quality of ECE can be described as a complex and controversial issue; therefore, it has become a focal point of ECE research in the past decades (Fenech 2011). According to research, high-quality ECE can widely enhance children's overall development and generate long-term effects in their learning (Sylva et al. 2010). Similarly, research has shown that engaging parents in children's education enhances the learning and development of children and prevents social problems (Goff, Evangelou \& Sylva 2012; Van Voorhis et al. 2013). Cooperation between parents and teachers is thus perceived as an integral part of quality ECE (NAEYC 2009).

As suggested by Sheridan et al. (2009), more research is needed on the quality of ECE in both national and international settings to determine the interdependency between different quality dimensions, such as the society, the users of the services and the cultural context (see also Sheridan 2007). Theory-based quality evaluation instruments, such as the one used in this study, consider the perspectives of different stakeholders, while enhancing knowledge of what is considered important in ECE, determining what goals are set for the pedagogical processes and what the child's perception is (Fonsén \& Vlasov 2017). Sharing information about the defined quality indicators among different stakeholders promotes understanding of the goals, strengths and areas to be further developed and increases awareness of childcare both nationally and internationally (Fonsén \& Vlasov 2017).

Additionally, cross-national research is a good way to achieve a better understanding on how childcare systems function in different societies and how quality aspects are assessed. Even though the perspective of the epistemic child (i.e. what children and all humans hold in common) is consistent from one culture to another, with the emergent increase in developing quality ECE, different societies conceptualise childhood culture in different ways (Smidt 2013; Tudge \& OderoWanga 2009). The structures of the society, its traditions and policy, regulate the reality of childhood as well as the reality of teachers' behaviours, which are ultimately defined as culture specific. Therefore, children and childhood are seen as cultural constructions. Cross-cultural research offers insights for assessing our own ECE culture and gaining new perspectives of the strengths and weaknesses of our own local practices when reflected against practices from other contexts. Cross-cultural studies do not focus on the inferiority or superiority of certain cultural 
differences. Rather, they propose to shed light on the cultural, historical and social influences in each society that have contributed to the shaping of the ECE system and have thus affected the perceived quality.

Bronfenbrenner's (1979) psychological concepts describing the systems around a growing child have given foundation for the comprehension of ECE as a contextually defined process that emphasises mutual interaction between a child and institutional settings (Hujala 1999). Later, Bronfenbrenner (1989) added 'time' as the concept identifying the way that people and environments change together. The core issue in this research is to study how parents' and teachers' opinions of ECE and its quality have changed in the timeline within the contexts of studied societies. Deriving from the theory of Bronfenbrenner, the study focuses on the integration (meso system) of the home and childcare centre (micro system) and how this interplay is influenced by the surrounding sociocultural context (macro system) in constant interaction. The macro level impacts and changes are thus examined within the notion of time.

Within this study frame, contextually defined ECE and its institutional programmes have been contextualised based on the studies of quality in ECE (Hujala, Fonsen \& Elo 2012). Operationalisation of the quality is based on the theoretically constructed quality evaluation model of ECE (Hujala et al. 2012). The quality model consists of structural variables describing programme setting, such as group size, process variables describing implementation and the practice of ECE and output variables describing child satisfaction with ECE. The infrastructure of programmes and also the processes and outputs are examined in this study from the child's perspective. This child perspective is gathered from parents and teachers because early education is seen as a parentteacher co-operative process (Hujala 2002; National Core Curriculum on Early Childhood Education and Care 2016). Scopelliti and Musatti (2013) argue that parents have a multifaceted view of childcare quality, which should be taken into account in order to form a more complete picture of the perceived quality of the services, although some researchers have questioned parents' abilities to reliably evaluate the quality of the services (Cryer \& Burchinal 1997; Cryer, Tietze \& Wessels 2002). According to contextual theory, a child is seen as inseparable from the surrounding context, and therefore the early education process should always be acknowledged as part of the reality in which the child lives (Hujala 2002). Cross-cultural research gives a perspective to examine how the ECE settings in a society-based context are functioning and what kind of role and impact ECE has in a child's life in a society-based context.

Previous studies offer limited information on how perceptions regarding the quality of the childcare services have changed in different societal contexts and what kind of ECE realities the differently organised services have produced. This article aims to address this gap by examining how the quality of ECE has changed in international settings over the past decades. By examining changes in parents' and teachers' quality assessments, this study endeavours to expand the perspectives regarding ECE and to broaden the comprehension of the diversity of the ECE phenomenon and its culture-specific nature. As mentioned above, the culture of education is always value bound. Cross-cultural research, such as this one, questions the self-evidences of culturally bound ECE practices by working as a reflective mirror to our own educational system and everyday practices. With a focus on the quality of ECE, this study examines key elements of the implementation of institutional and all-day-based ECE programme infrastructure, ECE curriculum goals, the integrated role of parents and teachers as partners in children's lives as well as children's satisfaction with their childcare. Ultimately, the article will shed light on paradigmatic changes in ECE quality research during the last two decades.

\section{Purpose of the study}

The purpose of this study is to report on the findings of a follow-up study, which examined parents' and teachers' perspectives on the quality of all-day childcare of 3- to 5-year-old children in the United States, Russia and Finland between 1991 and 2011. Current research in these three countries indicates different orientations in terms of how families and childcare centres influence each other. Specifically, in Russia, society has traditionally imposed a strong ideological power over families and education (Gradskova 2010; Taratukhina et al. 2006), whereas in the United States, childcare choices are dependent on the family's preferences and affordability without any federal or state interference (Barnett 2010; Bennett 2011). In Finland, ECE services are organised and steered by legislation. The municipalities in Finland are responsible for arranging childcare services for the families, based on their needs (Act on Early Childhood Education and Care 36/1973, revised in 2015; Karila 2012).

Cross-sectional data for the study were collected during three phases: 1991, 2001 and 2011, from the three society-based contexts. Research questions are informed by the following quality indicators (Hujala et al. 2012): (1) Structural quality indicators which concern variables of childcare settings; (2) Process indicators which are connected to the goals of ECE as well as home-school cooperation; and (3) Output indicators which concern children's satisfaction with ECE.

The following research questions directed the investigation:

1. What are the changes that occurred within childcare settings in the United States, Russia and Finland between 1991 and 2011?

2. What changes, if any, took place in parents' and teachers' congruence regarding educational goals of childcare in the United States, Russia and Finland between 1991 and 2011 ?

3. What changes, if any, happened in teachers' and parents' satisfaction with home-school cooperation in the United States, Russia and Finland between 1991 and 2011? 
4. What changes, if any, happened in teachers' and parents' views regarding children's satisfaction with their childcare in the United States, Russia and Finland between 1991 and 2011?

\section{Research methodology Participating centres and data collection}

Cross-sectional data were collected from parents and teachers of 3-5-year-old children in all-day childcare programmes in the United States, Russia and Finland between the years 1991 and 2011. The sample was collected from 19 ECE programmes in the three countries through purposive and convenience sampling techniques and thus represented a nonprobability sample. The first data set was collected in 1991, the second in 2001 and the third in 2011. In the United States, the data were collected in two cities in two different states. The first and second phase of data collection were carried out in Virginia, and the third data collection took place both in Virginia and in the State of New York. In Russia, the sample was obtained from a city near the Moscow metropolitan area, and in Finland the data were collected in a city in the east of the country. All locations for the research were urban areas with a university campus in each city. The research ethics were carefully considered throughout the project. All participants were duly informed of the research and the voluntary nature of it. The researchers visited each centre and instructed the teaching staff to hand out the surveys for the parents. The anonymity of the respondents was ensured, and the surveys were returned in sealed envelopes. The data were coded with participant numbers, and all personal info was deleted.

The study does not claim to represent the overall population of ECE services in the three societies, but to emphasise the contextual nature of the study. Originally, the chosen childcare centres represented a variety of centres in their societies. All the participating centres in each country were selected based on their proximity and willingness to participate in the study. Yet, it is necessary to bear in mind that the results cannot be overgeneralised to cover the entire sociocultural context of each country. Although generalisations are both impossible to achieve and undesirable, the study will yield new and important information about some of the society-related changes while contrasting the results from the three different sociocultural contexts within this study framework.

In the United States, there were originally five centres chosen for the study. Three of the centres were non-profit centres, including one that was operated by a religious affiliation, whereas two other centres were profit-orientated programmes. In the second phase of the study, only four centres participated, as one of them no longer existed. Before the third phase of the study, two centres had gone out of business and two centres declined participation for various reasons. Only one centre remained in the study, and two new centres were recruited to participate.
In Russia, in the first phase of data collection, five centres participated, three of them were operated by the state and two were owned by factories. In the second phase, four centres participated; one of the state-run public centres had changed their programme; therefore, it was excluded. In the third phase, three out of the original five centres participated, and by that time they were owned by the municipality.

In Finland, childcare centres are most commonly owned and operated by municipalities. In the first phase of the study, seven municipal childcare centres participated. During the second phase, only four centres participated because one centre had closed down and two centres declined participation because of the amount of work they had at that time. In the third phase, six centres took part. One centre had changed their programme and did not meet the selection criteria any more. In addition, the previously closed centre had reopened and re-entered into the study. Overall, the centres were the same ones throughout the entire study; however, their number varied throughout the phases of data collection.

The data were collected from the parents and teachers by means of questionnaires. As shown in Table 1, the return rates of the questionnaires demonstrate a great variation among the countries and the years when the data were collected.

The return rates from teachers in every country were high during all of the phases, except for the second phase in the United States. Similarly, return rates from parents in the United States were overall low, especially during the second phase in 2001. In Finland and Russia, the return rates among parents also declined over the years. In contrast, in the United States, the return rates were highest during the last phase. In addition, the parent participants in Russia were the most committed to the research cooperation; their return rates were the highest in all phases compared to parents from the United States and Finland.

\section{Research instrument}

The research instrument was a printed questionnaire for parents and teachers. The questionnaires for both respondent groups were child-specific in nature, meaning that parents and teachers were asked to answer the questions from the

TABLE 1: Questionnaire return rates (\%) and number of participating parents and teachers in the study.

\begin{tabular}{lcccccc}
\hline Country & Cohort & \multicolumn{2}{c}{ Parents } & & \multicolumn{2}{c}{ Teachers } \\
\cline { 3 - 4 } \cline { 6 - 7 } & & $\begin{array}{c}\text { Return rate } \\
(\mathbf{\%})\end{array}$ & Final sample & & $\begin{array}{c}\text { Return rate } \\
\mathbf{( \% )}\end{array}$ & Final sample \\
\hline United States & 1991 & 57 & 88 & & 100 & 166 \\
& 2001 & 36 & 56 & & 49 & 96 \\
& 2011 & 78 & 97 & & 100 & 122 \\
Russia & 1991 & 99 & 172 & & 94 & 173 \\
& 2001 & 94 & 187 & & 97 & 189 \\
& 2011 & 89 & 200 & & 96 & 215 \\
\multirow{2}{*}{ Finland } & 1991 & 79 & 117 & & 100 & 150 \\
& 2001 & 56 & 61 & & 82 & 87 \\
& 2011 & 55 & 145 & & 98 & 249 \\
\hline
\end{tabular}


point of view of each individual child and family. Therefore, teachers filled out questionnaires for each single child in their classroom considering their individual ECE needs. In addition, participating parents and teachers were asked to assess and rank the seven goals of the ECE programme. These goals were emotional, social, cognitive, health, ethical, religious and aesthetical. They were asked to evaluate the childcare goals from the perspective of how important they were for each child, and their developmental needs. The respondents were asked to rank three most important goals by using the following items: (1) The child's health is taken care of and it is taught to take care of its own health by itself; (2) The child has contact with other people outside home and learns communication with children and adults of different ages; (3) The child feels acceptance and emotionally secure as well as learns to respect other people; (4) The child is guided to observe beauty in its different forms and by that helped to develop its imagination; (5) The child is taught different kind of skills and helped to develop its capacity for learning; (6) The child is taught to behave honestly in its human relationships and to love its environment and to take a negative attitude towards violence; (7) The child is supported to search for information about its own religion and culture as well as the tradition of celebrating holidays.

Both respondent groups were also asked about their satisfaction with parent-teacher cooperation and about the children's satisfaction with childcare as they - teachers and parents - perceived the child's satisfaction. The structured quality assessment items were based on the 1-5 Likert rating scale. The questionnaire was developed by a Finnish researcher in cooperation with the US researchers in the early 1990s.

The research ethics were carefully observed during the course of the project. All participants were informed of the research and the voluntary nature of participation, and their consent to participate was requested and received. The directors and the staff members in each childcare centre were trained in properly delivering the questionnaires to parents and teachers. The anonymity of the respondents was ensured. The data from the questionnaires were coded by using participant numbers in order to match the parents' and teachers' responses representing the same child, in order to be able to compare and contrast the parents' and teachers' views.

\section{Data analysis}

The data were analysed as separate case studies from each society and from each time cohort. Quantitative reporting was based on frequencies and percentages of the data as well as an analysis based on multivariate methods (Creswell 2002). The goal was to analyse the changes in teachers' and parents' views regarding childcare in Russia, the United States and Finland.

In analysing teachers' and parents' opinions regarding the goals of ECE, their rankings were coded so that the most important was weighted by three, the second by two and the third important by one. Then summative rankings were used in comparing the goals between parents and teachers in the studied societies.

To study the society effect and time cohort effect to the dependent variables (home-school cooperation, children's satisfaction with ECE), we used two-way variance analyses (Cohen, Manion \& Morrison 2003). In the studied groups, the homogeneity of variances was examined by using Levene's test of Equality of Error Variance. In those cases where homogeneity requirements were met, the Scheffe test was used. However, in those cases where the test showed that the requirements for homogeneity of the variances were not met, we used Dunnett's test to run the multiple comparisons between the three countries. In addition, the distribution of the variables was examined, although the number of cases (n) in all researched samples varied from 76 to 248 and was large enough to guarantee proceeding with the analysis.

\section{Results \\ Changes in childcare settings in the United States, Russia and Finland}

The first research question focuses on changes in structural factors of quality, that is, childcare settings in the United States, Russia and Finland between 1991 and 2011. This information was gathered from the childcare centres participating in the study, and the means are presented in Table 2. The results show that although there were differences in the structural quality variables between participating countries, the variables remained quite stable during the study period.

The group sizes are biggest in Russia (27, 24 and 25 children per group) and smallest in the United States (17, 13 and 15 children per group), which stays consistent throughout the years as Table 2 indicates. The adult-child ratio is the smallest (1:8, 1:6 and 1:6) in Finland and the biggest in the United States $(1: 9,1: 10)$. The exception for the United States is for the last phase (2011), when the ratio declined to 1:8. It is important to note that in 2011 the ratio increased remarkably high to 1:12 in Russia, which could be explained by the fact that only teachers were considered to form a team, and the assistants were excluded from participating in this research in Russia at that time. In Finland and in the United States, teachers and assistant teachers were considered for calculating the ratio.

\section{Goals of childcare}

The second research question concerns the process of ECE quality: What changes, if any, took place in parents' and teachers' congruence regarding educational goals of childcare in the United States, Russia and Finland between 1991 and 2011? The study targeted the goals of childcare programmes based on parents' and teachers' perspectives. Based on children's developmental needs, seven goals for ECE were formulated in the questionnaire. These goals were emotional, social, cognitive, health, ethical, religious and aesthetical. The respondents ranked the seven goals from most to least 
TABLE 2: Centre-based information on structural quality indicators in childcare settings in the United States, Finland and Russia by cohorts.

\begin{tabular}{|c|c|c|c|c|c|c|c|c|c|}
\hline \multirow{2}{*}{$\begin{array}{l}\text { Structural quality indicators in ECE } \\
\text { settings }\end{array}$} & \multicolumn{3}{|c|}{ United States } & \multicolumn{3}{|c|}{ Finland } & \multicolumn{3}{|c|}{ Russia } \\
\hline & 1991 & 2001 & 2011 & 1991 & 2001 & 2011 & 1991 & 2001 & 2011 \\
\hline Group size & 17 & 13 & 15 & 19 & 22 & 20 & 27 & 24 & 25 \\
\hline Number of teachers & 2.0 & 1.4 & 2.0 & 3.0 & 3.6 & 3.2 & 3.2 & 2.8 & 2.0 \\
\hline Adult-child ratio & 1:9 & $1: 10$ & $1: 8$ & $1: 8$ & $1: 6$ & $1: 6$ & $1: 9$ & 1:9 & $1: 12$ \\
\hline
\end{tabular}

ECE, early childhood education.

TABLE 3: Teachers' and parents' opinions of the three most important goals for centre-based early childhood education in the United States, Russia and Finland by cohorts.

\begin{tabular}{|c|c|c|c|c|c|c|c|}
\hline & \multirow[b]{2}{*}{ Cohort } & \multicolumn{2}{|c|}{ United States } & \multicolumn{2}{|c|}{ Finland } & \multicolumn{2}{|c|}{ Russia } \\
\hline & & Teachers & Parents & Teachers & Parents & Teachers & Parents \\
\hline \multirow{3}{*}{$\begin{array}{l}\text { Most } \\
\text { important }\end{array}$} & 1991 & Emotional & Emotional & Social & Social & Health & Health \\
\hline & 2001 & Emotional & Emotional & Social & Social & Health & Health \\
\hline & 2011 & Emotional & Emotional & Social & Emotional & Health & Cognitive \\
\hline \multirow{3}{*}{$\begin{array}{l}\text { Second } \\
\text { important }\end{array}$} & 1991 & Cognitive & Social & Emotional & Emotional & Cognitive & Cognitive \\
\hline & 2001 & Cognitive & Cognitive & Emotional & Emotional & Cognitive & Cognitive \\
\hline & 2011 & Cognitive & Health & Emotional & Social & Cognitive & Social \\
\hline \multirow{3}{*}{$\begin{array}{l}\text { Third } \\
\text { important }\end{array}$} & 1991 & Social & Cognitive & Cognitive & Ethical & Emotional & Ethical \\
\hline & 2001 & Health & Social & Cognitive & Ethical & Social & Social \\
\hline & 2011 & Social & Social & Cognitive & Cognitive & Emotional & Health \\
\hline
\end{tabular}

important in terms of development of children in a childcare setting. Parents and teachers were asked to assess the goals of childcare according to every individual child and how these goals were perceived to support the child's development.

An examination of the rank-ordered goals indicates that both respondent groups (teachers and parents) within all societies (USA, Finland and Russia) agreed unanimously on the most important goal of ECE in all cohorts. In addition, among the teachers (regardless of their country) there is consistency in assessing the most and even the second most important goals during the research period.

In the United States, teachers emphasise children's emotional development as the most important goal of ECE. Finnish teachers emphasise the child's social development, and Russian teachers emphasise supporting children's health as the most important goal of ECE. Only in the last cohort (in 2011) were there differences between teachers' and parents' views on the goals of ECE. Whereas Finnish parents in the last cohort had changed their views to prefer emotional development as the most important ECE goal, more than to support the child's social development, teachers' opinions stayed the same. They still valued social education as the most important goal of ECE. In Russia, teachers have traditionally and consistently considered health education as the most important goal in childcare. However, in 2011, the emphasis changed among the Russian parents from health to the support of cognitive development as the most important goal of ECE. Only in the United States did the agreement in parents' and teachers' opinions concerning the most important goal remain consistent during the 20 years of the research period.

There was an interesting difference between the studied societies in supporting children's ethical development as a goal of ECE. In the United States, ethical education was not at all regarded as important by the participants. Among Russian parents, supporting the child's ethical development was seen as the third most important ECE goal, but only during the first cohort. Finnish parents assessed supporting the child's ethical development as the third most important goal of ECE in the first and second cohort, whereas in the third cohort they regarded support of the child's cognitive development as a more important goal for ECE. The results indicate that Russian and Finnish early education culture has a strong value to support children to grow up as human beings. The Act on Children's Day Care (1973) in Finland emphasised this. Does this change in parents' ECE preferences mean that the drive to success in the knowledge society is going to replace human values in ECE?

\section{Teachers' and parents' satisfaction with home- school cooperation}

The third research question examined the possible changes in teachers' and parents' satisfaction with home-school cooperation in the studied societies. The respondents assessed their satisfaction from the point of view of each individual child and family.

The results of variance analysis concerning teachers' satisfaction with home-school cooperation in the United States, Russia and Finland within three time cohorts suggest that there were no statistically significant differences in the main effects, that is, between countries and between time cohorts. However, the country and time cohort had an interaction effect $[F(4)=2.65 ; p<0.05]$ that was statistically significant. In examining the results more carefully, Figure 1 shows that Russian teachers' satisfaction with home-school cooperation stayed quite the same in all studied cohorts. In Finland and in the United States, there was interesting coherence in teachers' views between these countries in the first and second cohort, but in the last cohort there was a difference in US and Finnish teachers' satisfaction with home-school cooperation. The change in teachers' satisfaction was opposite to each other: US teachers' 
satisfaction stayed at a very similarly low level; however, Finnish teachers' satisfaction significantly increased during the last decade.

In examining parents' satisfaction with home-school cooperation, the country and time cohort had an interaction effect $[F(4)=7.01 ; p<0.001]$ that was statistically very strong. Figure 2 shows that in Russia and in Finland, parents' satisfaction with home-school cooperation increased in two decades; however, in the United States, it decreased over the same time period.

In addition, there was a statistically significant difference between countries $[F(2)=22.14 ; p \leq 0.001]$. The significant

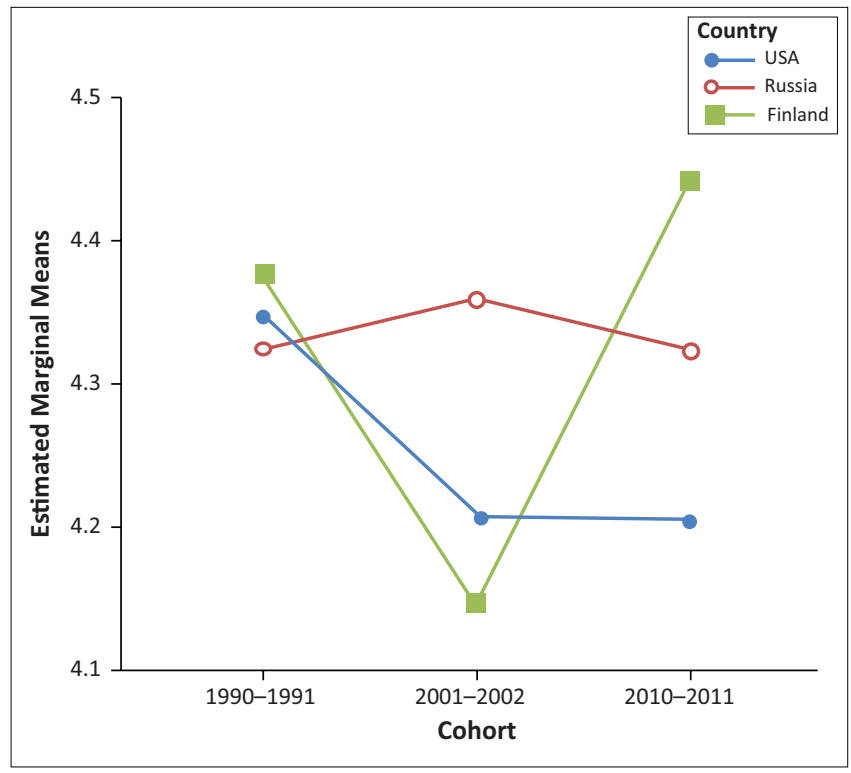

FIGURE 1: Teachers' satisfaction with home and school cooperation in two decades in the United States, Russia and Finland ( $1=$ least satisfied; $5=$ most satisfied).

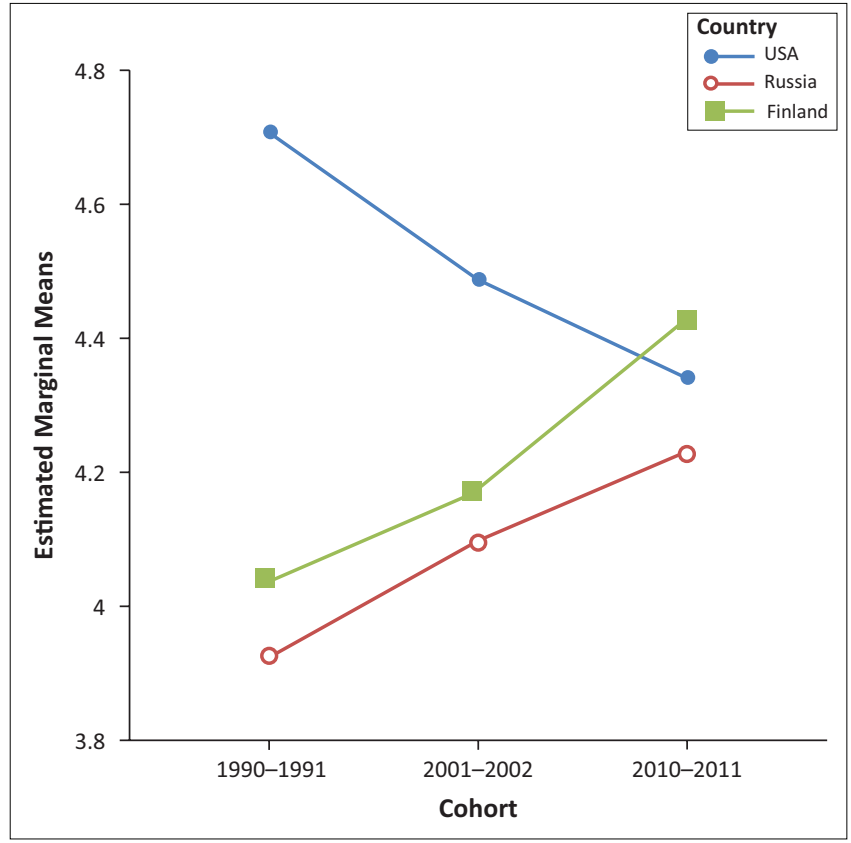

FIGURE 2: Parents' satisfaction with home-school cooperation in two decades in the United States, Russia and Finland ( $1=$ least satisfied; $5=$ most satisfied). difference was between the United States and Russia $(p<0.001)$ and the United States and Finland $(p<0.001)$, and a slightly significant difference between Finland and Russia $(p<0.05)$. According to the means, the parents' satisfaction with cooperation during the studied period was lowest in Russia $(x=4.07)$ and highest in the United States $(x=4.53)$.

\section{Teachers' and parents' views regarding child's satisfaction with childcare}

Research question 4 targeted the changes in teachers' and parents' views regarding children's satisfaction with their childcare. Regarding the results, there was a statistically significant $[F(4)=4.16 ; p<0.01]$ interaction effect of the country and time cohort. Figure 3 shows that according to Russian teachers, children's satisfaction with childcare centres increased during the two decades. On the other hand, children's satisfaction strongly decreased in the US centres during the last decade. In Finland, children's satisfaction with ECE remained the same during the three time cohorts.

In results concerning the main effects of variance analysis, there was a statistically significant difference $[F(2)=33.40$; $p<0.001$ ] between the countries in children's satisfaction with childcare. Russian teachers perceived children's satisfaction as lower $(x=3.83)$ than that of their US and Finnish counterparts. Teachers' perceptions of child satisfaction in Finland $(x=4.17)$ and in the United States $(x=4.18)$ were almost equal without any statistical difference.

Figure 4 shows that in parents' perceptions of children's satisfaction with childcare, there are no significant differences between United States, Russia and Finland in interaction effect of the country and time cohort. In addition, there was

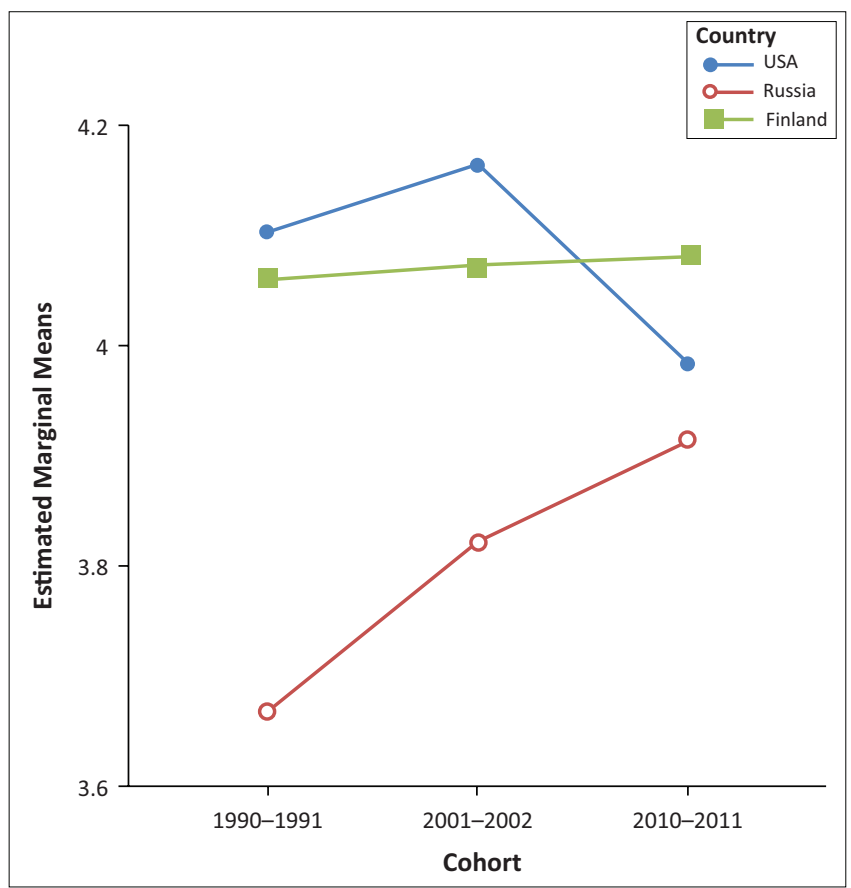

FIGURE 3: Teachers' views about child's satisfaction with childcare ( $1=$ least satisfied; $5=$ most satisfied). 


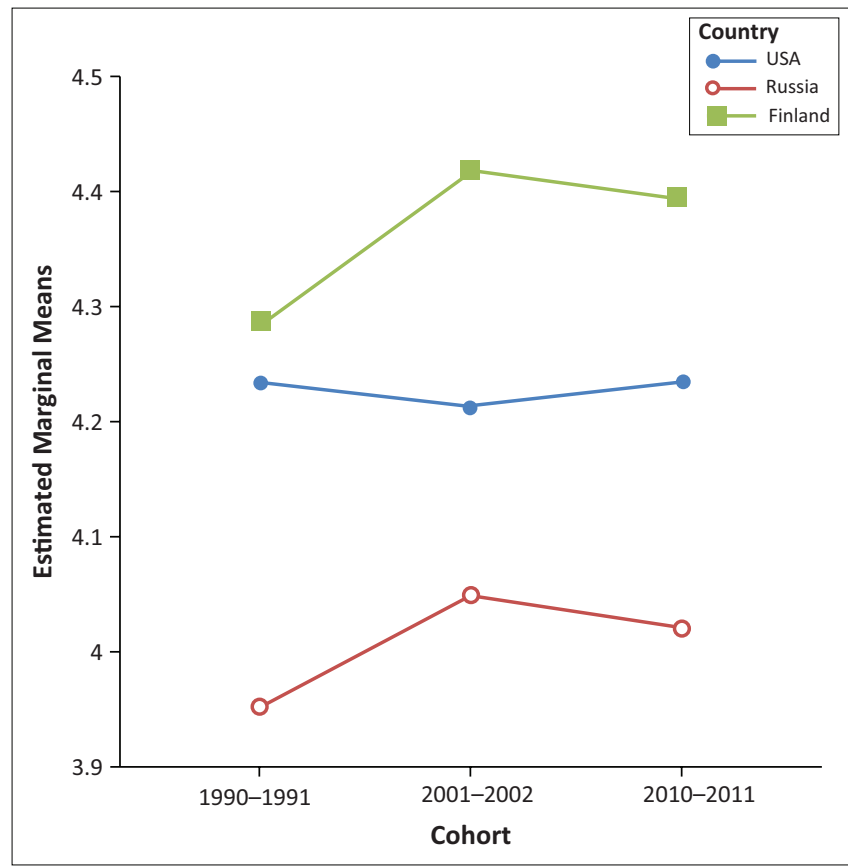

FIGURE 4: Parents' perceptions of child's satisfaction with childcare ( 1 = least satisfied; $5=$ most satisfied).

no main effect of the cohort either. However, the main effect, that is, effect of the country, was statistically significant $[F(2)=$ 26.58; $p<0.001]$. In all the cohorts, Finnish parents assessed children's satisfaction with childcare programme the highest $(x=4.38)$ in comparison with parents in the United States and Russia. Specifically, in the United States, the mean of parents' assessments was $x=4.23$ and in Russia the mean of parents' assessments was $x=3.99$, being the lowest in studied societies.

\section{Discussion}

This article focused on parents' and teachers' perspectives regarding the quality of all-day childcare of 3- to 5-year-old children in the United States, Russia and Finland. The study took place between 1991 and 2011, and the quantitative data were collected during three phases. During the study period, a big societal change took place in all three societies. In Russia, Perestroika changed the whole paradigm of the politics, transforming the society from communism into free enterprise. In Finland, the economic recession early in the 1990s challenged the status of the welfare state, which was followed by growing privatisation of the public sector. In the United States, values emphasising free and private market strengthened in the 1990s and reduced the importance of and support for human services, such as childcare (Hujala 2004). This current study focused on the possible changes in childcare, which were generated by the political and economic changes in the three countries.

When analysing the structural indicators of ECE quality, the results suggested that centre characteristics in the studied societies remained consistent during the study period, and the differences between the societies remained intact. The structural quality factor refers to the physical and psychological conditions of the ECE culture including group sizes or facilities, which regulate pedagogical activities. The group sizes in the early childhood classrooms in the United States were the smallest in the studied centres, though in the Finnish context the child-teacher ratio was the lowest. According to the Finnish Act on Early Childhood Education and Care (1973/2015), the highest ratio is eight children and one teacher in a child group of 3- to 5-year-old children. In the United States and Russia, the child-staff ratios were very similar. In terms of the group size, the results indicate that smaller groups are valued in the United States more than in other countries. Although the data were collected from two different states - New York and Virginia during the third phase, the group sizes remained consistent regardless of the differences among the states concerning the childcare regulations. Parents and teachers in the American individual culture (Rosenthal 2003; Tobin, Wu \& Davidson 1989; Triandis 1994) appreciate teachers working one-on-one with the children (Bredekamp \& Rosegrant 1992). In Russia, which in contrast has been traditionally considered a collectivist society (Rosenthal 2003; Triandis 1994), the groups are bigger. According to research (Gradskova 2010; Ispa 2002), Russian ECE culture has traditionally emphasised teachers' authoritarian role, and children have been expected to show good behaviour and a great amount of self-control. Thus, with more discipline in a group, one teacher can 'handle' more children. In Finland, group sizes remain a contentious and ongoing topic in childcare. In Finland, the tradition of group-focused didactics is still guiding the pedagogical thinking of teachers (Kalliala 2012). It seems that in the Finnish ECE context, teacher resources and the benefit of low ratio are not yet optimally embraced, and the advantages of small ratios have not yet been fully utilised when making pedagogical decisions. For example, small group pedagogy and an individual approach have not yet been implemented in child rearing and teaching to an extent to which they would be possible (Kangas 2016).

The second research question dealt with the goals of ECE. The results suggest that the goals of the programmes are culturally defined to a great extent, and they mirror the way the society perceives children and their education. The longitudinal nature of the study indicates slow societal changes in the educational goals. In all of the three society contexts, teachers' views concerning the most important and second most important goals in childcare remained the same in each society during the two decades. However, teachers' views concerning the important ECE goals were totally different and varied between the countries. Teachers' and parents' congruence concerning the ECE goals inside the society were very consistent. The results of the study demonstrate that the perceptions of formal educational institutions remained largely unchanged, although the societies around them changed. Rosenthal (2003) argues that goal definitions in ECE reflect the roots of childhood and the roots of early education. 
In Finland, as well as in other Nordic countries, ECE is strongly rooted in social service (Einarsdottir 2003; FolkeFichtelius 2004) and the support of children's social development is therefore emphasised. According to Vlasov and Hujala (2016), parents' awareness of institutional childcare in the contexts of the United States, Russia and Finland has increased over the past 20 years, which adds to the need to enhance the visibility of childcare services, their ideology and educational goals.

When examining the third research question, it can be noted that both teachers' and parents' satisfaction with parentteacher cooperation has increased greatly during the last phase of the study in the Finnish context. Between the second and third phase, the National Curriculum Guidelines for ECE (2005) were introduced in Finland. Those guidelines particularly emphasised parents' participation in ECE. Based on the results of this study, teachers' efforts in parent involvement seem to have been successful. In contrast, in the United States, parents' and teachers' satisfaction with parent-teacher cooperation has decreased. In the US context, focusing on parent-teacher cooperation has long traditions. In their study of parent-teacher partnerships in the US context, Powell and Diamond (1995) demonstrate how parents' role has changed from perceiving them as learners towards being partners in the collaboration process. In addition, during the recent decades, forming partnerships with families has questioned the traditional view on parental involvement and thus created a need to better prepare future educators to collaborate with families (Epstein 2013; Miller et al. 2013). Although the emphasis is now placed on reciprocal partnerships with parents (NAEYC 2009), the increasing demands for better learning outcomes and achievement still seem to emphasise the professional superiority of teachers in the cooperation process (Vlasov \& Hujala 2017). In line with McGrath (2007), professionals' educative stance towards parents may lead to a power imbalance in the cooperation process and thus reflect negatively in the evaluation of the cooperation. In Russia, parents' satisfaction with cooperation has increased, but teachers' satisfaction remained quite the same during the study period. As suggested by other studies, the role of parents in Russian ECE has changed significantly from the parents' subordinate role to a more cooperative stance during the recent years (Gradskova 2010; Taratukhina et al. 2006; Vlasov et al. 2016). Empowering parents in their child's early education process is most likely to lead to parents' increased satisfaction with cooperation. Yet, the changed role of parents as clients challenges the current forms of parent-teacher cooperation in each society and adds pressure in developing the processes as well as reconceptualising the global quality norms for educational collaboration (Vlasov and Hujala 2016). Parents' awareness of institutional childcare has increased, which adds to the need to enhance the visibility of childcare services, their ideology and educational goals as well as the enacted parent-pedagogue partnership: today's parents are more demanding and their expectations are higher than before (Vlasov and Hujala 2016).
Child satisfaction with childcare, as perceived by parents and teachers, has been evaluated the lowest by Russian teachers and parents in all studied cohorts. Finnish parents have seen children's satisfaction with childcare as being high in all cohorts. In Finnish ECE, the emphasis to involve parents more and more in their children's early education process has increased during the past years. Participative parents are supportive for children's well-being and aware of children's satisfaction with the programme. In contrast, the opinions of the US teachers concerning children's satisfaction with childcare have decreased during the last cohort. As suggested by Scopelliti and Musatti (2013), the more parents value the different components of ECE quality, such as their child's experiences and cooperation with the caregivers, the better they seem to evaluate the different aspects of the childcare quality.

To conclude, this study provided evidence for how the society and culture mould ECE in different contexts. When reflecting on the results concerning the cooperation and child satisfaction, the society variable was a stronger explanatory factor than the time cohort was. Sociocultural realities and the values of each society context can be perceived to be reflected in the ECE curriculum. The values of each sociocultural context become visible in the pedagogy and in the ways teachers as well as parents interact with children. The theory of Bronfenbrenner (1979) as well as the contextual theory of child's growth (Hujala 1999) provided a useful ontological foundation for the study. Instead of using the theories to directly guide the analysis process, they provided an interesting frame to analyse parents' and teachers' perspectives on key elements of the implementation of ECE in childcare centres: programme structure, curriculum goals, the role of parents and teachers as partners in children's lives as well as children's satisfaction with their childcare. According to the theories, societal values and attitudes, as well as choices and solutions, guide the implementation of settings in a child's life context. The growth setting can be perceived as a resource for the child's growth, but it may also hinder it. What kind of resources it gives, or what kind of limitations it constructs, depends on how emancipated the child as a subject is in relation to the structure of the given sociocultural system (Hujala 1999).

\section{Concluding remarks}

In addition to the changes concerning the empirical results of the study, the changes related to the research paradigms and the data collection methods during the long research period challenged the researchers. Because of the fact that the study period spans over two decades, both the methodological issues and research strategies have changed. Therefore, it was necessary to analyse this as well. In the late 1980s and early 1990s, when the research instruments were created, ECE was seen to have its foundations in the psychological paradigm and thus the psychological concepts (Hujala 2008; Scarr \& Eisenberg 1993). For example, the goals of ECE were defined according to the domains of child development, for example cognitive, emotional and physical. Today, the main 
theories and the widely used concepts in ECE and in its research derive from the paradigm of early education. Currently, ECE is seen as an early learning process constructed in interaction with children and teachers. Additionally, the comprehension of the participants in ECE research has changed. Whereas 20 years ago, the parents as primary caregivers were considered to have the best knowledge of their children, for example how satisfied they were with childcare (Scarr \& Eisenberg 1993), today, according to the United Nations Convention on the Rights of the Child (1989), every child should have a right to be heard on matters that affect their lives. Thus, the perception of children as direct informants in matters concerning their own life is prevalent in ECE research.

One of the tasks of the present study is acknowledging the cultural differences in implementing academic research, which can also be seen as a limitation of the study. As the results show, the differences in questionnaire return rates between the countries were obvious. In Finland and Russia, especially the teachers feel that participating in research is part of the ECE professionalism, and this directly related to their ECE work. In contrast, in the United States during the second data collection phase the researchers were advised that participants in the United States are used to getting monetary compensation for taking part in a study. As the research project was led from Finland, the project was not prepared to pay the participants because of differences in the research culture in European context. Having learned from that experience, during the third phase the participants were paid some compensation in the United States and offered other kinds of material compensation in Finland and in Russia.

\section{Acknowledgements}

Mervi Eskelinen as a master's student at University of Tampere has contributed to the article in conducting statistical calculations of the study

\section{Competing interests}

The authors declare that they have no financial or personal relationships which may have inappropriately influenced them in writing this article.

\section{Authors' contributions}

E.H. was the project leader, being responsible for experimental and project design. E.H., J.V. and T.S. made conceptual contributions. E.H. and J.V. performed the analysis based on statistical data. Interpretations of analysed findings and reflections of the results were performed by E.H., J.V. and T. S.

\section{References}

Act on Children's Day Care 36/1973, Laki lasten päivähoidosta 36/1973, Ministry of Justice, Finland.

Act on Early Childhood Education and Care 36/1973 (Revised Act on Children's Day Care 36/1973 in 2015), Varhaiskasvatuslaki 36/1973, Ministry of Justice, Finland.

Barnett, W.S., 2010, 'Universal and targeted approaches to preschool education in the United States', International Journal of Child Care and Education Policy 4(1), 1-12. https://doi.org/10.1007/2288-6729-4-1-1
Bennett, J., 2011, 'Early childhood education and care systems: Issue of tradition and governance', in R.E. Tremblay, M. Boivin \& R.D.V. Peters (eds.), Encyclopedia on early childhood development, pp. i-iv, Centre of Excellence for Early Childhood early childhood development, pp. i-iv, Centre of Excellence for Early Childhood
Development and Strategic Knowledge Cluster on Early Child Development, Montreal, QC, viewed 15 May 2016, from http://www.child-encyclopedia.com/ Montreal, QC, viewed 15
pages/PDF/child_care.pdf

Bredekamp, S. \& Rosegrant, T. (eds.), 1992, Reaching potentials: Appropriate curriculum and assessment for young children, National Association for the Education of Young Children, Washington, DC.

Bronfenbrenner, U., 1979, The ecology of human development, Harvard University Press, Cambridge, MA.

Bronfenbrenner, U., 1989, 'Ecological systems theory', in R. Vasta (ed.), Annals of child development, vol. 6, pp. 187-249, JAI Press, Greenwich, CT.

Cohen, L., Manion, L. \& Morrison, K., 2003, Research methods in education, 5th edn., Routledge, London.

Creswell, J., 2002, Educational research: Planning, conducting, and evaluating quantitative and qualitative research, Prentice Hall, Saddle River, NJ.

Cryer, D. \& Burchinal, M., 1997, 'Parents as child care consumers', Early Childhood Research Quarterly 12, 35-58. https://doi.org/10.1016/S08852006(97)90042-9

Cryer, D., Tietze, W. \& Wessels, H., 2002, 'Parents' perceptions of their children's child care: A cross-national comparison', Early Childhood Research Quarterly 17, 259-277. https://doi.org/10.1016/S0885-2006(02)00148-5

Einarsdottir, J., 2003, 'The role of preschool teachers: Icelandic preschool educators' discourses', Early Years 23(2), 103-116. https://doi.org/ $10.1080 / 09575140303110$

Epstein, J.L., 2013, 'Ready or not? Preparing future educators for school, family, and community partnerships', Teaching Education 24(2), 115-118. https://doi.org/10. 1080/10476210.2013.786887

Fenech, M., 2011, 'An analysis of the conceptualisation of "quality" in early childhood education and care empirical research: Promoting "blind spots" as foci for future research', Contemporary Issues in Early Childhood 12(2), 102-117. https://doi. org/10.2304/ciec.2011.12.2.102

Folke-Fichtelius, M., 2004, 'Care and/or education? Tensions in Swedish childcare policy', paper presented at NFPF Conference in Reykjavik, 28th April.

Fonsén, E. \& Vlasov, J., 2017, 'Leading pedagogical quality in the context of Finnish child care', in C. Ringsmose \& G. Kragh-Müller (eds.), Nordic social pedagogical approach to early years, International perspectives on early childhood education approach to early years, International perspectives on early childhood education and development, vol.
265 , Springer, Cham.

Goff, J., Evangelou, M. \& Sylva, K., 2012, 'Enhancing parents' ways of supporting their children's early learning through participation in an early-intervention project in the UK: The early learning partnership project', Zeitschrift für Familienforschung the UK: The early $160-177$.
24)

Gradskova, Y., 2010, 'Educating parents: Public preschools and parenting in Soviet pedagogical publications, 1945-1989', Journal of Family History 35, 271-285. https://doi.org/10.1177/0363199010368775

Hujala, E., 1999, 'Challenges for a childhood in a changing society', in H.K. Chiam (ed.), Towards excellence in early childhood education, pp. 135-154, University of Malaya, Kuala Lumpur.

Hujala, E., 2002, 'The curriculum for early learning in the context of the society', International Journal of Early Years Education 10(2), 95-104. https://doi. org/10.1080/09669760220141980

Hujala, E., 2004, 'Early childhood education and care in a changing society International reflections', in M. Lundkvist \& C. Öhberg (eds.), Det synliga barnet Praktiska och teoretiska perspektiv på pedagogiken. Festkrifg tillägnad Marita Lindahl, Rapport 9/2004, pp. 119-130, Åbo, Akademi.

Hujala, E., 2008, 'The development of early childhood education as an academic discipline in Finland', Nordisk Barnehageforskning 1(1), 17-23. https://doi. org $/ 10.7577 /$ nbf.238

Hujala, E., Fonsen, E. \& Elo, J., 2012, 'Evaluating the quality of the child care in Finland', Early Child Development and Care 182(3-4), 299-314. https://doi.org/10.1080/0300 4430.2011 .646721

Ispa, J.M., 2002, 'Russian child care goals and values: From Perestroika to 2001', Early Childhood Research Quarterly 17, 392-413. https://doi.org/10.1016/S08852006(02)00171-0

Kalliala, M., 2012, Lapsuus hoidossa? Aikuisten päätökset ja lasten kokemukset päivähoidossa [Taking care of childhood? Decisions of adults and experiences of children], Gaudeamus, Helsinki.

Kangas, J., 2016, Enhancing children's participation in early childhood education with participatory pedagogy, Faculty of Behavioral Science, University of Helsinki, Helsinki.

Karila, K., 2012, 'A Nordic perspective on early childhood education and care policy', European Journal of Education 47(4), 584-595. https://doi.org/10.1111/ejed. 12007

McGrath, W.H., 2007, 'Ambivalent partners: Power, trust and the partnership in relationships between mothers and teachers in a full-time childcare centre', Teachers College Record 109(6), 1401-1422.

Miller, G.E., Lines, C., Sullivan, E. \& Hermanutz, K., 2013, 'Preparing educators to partner with families', Teaching Education 24(2), 150-163. https://doi.org/10.108 $0 / 10476210.2013 .786889$

Moss, P., 2012, 'Caring and learning together: Exploring the relationship between parental leave and early childhood education and care', European Journal of Education 47(4), 482-493. https://doi.org/10.1111/ejed.12003 
NAEYC, 2009, Developmentally appropriate practice in early childhood programs serving children from birth through age 8 (Position statement), National serving children from birth through age 8 (Position statemer
Association for the Education of Young Children, Washington, DC.

National Board, 2016, National core curriculum on early childhood education and care, 2016, The Finnish National Board of Education, Helsinki.

National curriculum guidelines on early childhood and care in Finland, 2005, Stakes, Oppaita 56, viewed 20 February 2017, from http://urn.fi/URN:NBN:fi-fe20120 4193910

Powell, D.R. \& Diamond, K.E., 1995, 'Approaches to parent-teacher relationships in U.S. early childhood programmes during the twentieth century', Journal of Education 177(3), 71-94.

Rosenthal, M.K., 2003, 'Quality in early childhood education and care: A cultural context', European Early Childhood Education Research Journal 11(2), 101-116. https://doi.org/10.1080/13502930385209191

Scarr, S. \& Eisenberg, M., 1993, 'Child care research: Issues, perspectives, and results', Annual Review Psychology 44, 613-644. https://doi.org/10.1146/annurev. ps.44.020193.003145

Scopelliti, M. \& Musatti, T., 2013, 'Parents' view on child care quality: Values, evaluations and satisfaction', Journal of Child and Family Studies 22(8), 10251038. https://doi.org/10.1007/s10826-012-9664-3

Sheridan, S., 2007, 'Dimension of pedagogical quality in preschool', International Journal of Early Years Education 15, 197-217. https://doi.org/10.1080/ 09669760701289151

Sheridan, S., Giota, J., Han, Y.M. \& Kwon, J.Y., 2009, 'A cross-cultural study of preschoo quality in South Korea and Sweden: ECERS evaluations', Early Childhood Research Quarterly 24, 142-156. https://doi.org/10.1016/j.ecresq.2009.03.004

Smidt, S., 2013, The developing child in the 21st century. A global perspective on child development, Routledge, London.

Sylva, K., Melhuish, E., Sammons, P., Siraj-Blatchford, I. \& Taggart, B. (eds.), 2010, Early childhood matters: Evidence from the Effective Pre-school and Primary Education (EPPE) project, Routledge, London.
Taratukhina, M.S., Polyakova, M.N., Berezina, T.A., Notkina, N.A., Sheraizina, R.M. \& Borovkov, M.I., 2006, Early childhood care and education in the Russian Federation, background paper for EFA Global Monitoring Report 2007: Strong foundations: Early childhood care and education, 2007/ED/EFA/MRT/PI/29, foundations: Eary
UNESCO, Paris.

Tobin, J.J., Wu, D.Y.H. \& Davidson, D.H., 1989, Preschool in three cultures, Yale University Press, New Haven, CT.

Triandis, H.C., 1994, Culture and social behaviour, McGraw-Hill, New York.

Tudge, J. \& Odero-Wanga, D., 2009, 'A cultural-ecological perspective on early childhood among the luo of Kisumo, Kenya', in M. Fleer, M. Hedegaard \& J. Tudge (eds.), Childhood studies and the impact of globalization: Policies and practices at global and local levels, pp. 142-160, Routledge, New York.

UN General Assembly, 1989, Convention on the rights of the child, Treaty Series, vol. 1577, p. 3, United Nations, viewed 10 February 2017, from http://www.refworld. org/docid/3ae6b38fo.html

Van Voorhis, F.L., Maier, M.F., Epstein, J.L., Lloyd, C.M. \& Leung, T., 2013, The impact of family involvement on the education of children ages 3 to 8: A focus on literacy and math achievement outcomes and social-emotional skills, Executive Summary, MDRC, viewed 13 February 2017, from http://www.mdrc.org/sites/default/files/ The_Impact_of_Family_Imvolvement_ES.pdf

Vlasov, J. \& Hujala, E., 2016, 'Cross-cultural interpretations of changes in early childhood education in the USA, Russia, and Finland', International Journal of Early Years Education 24(3), 309-324. https://doi.org/10.1080/09669760.2016.1 Early Years
189812

Vlasov, J. \& Hujala, E., 2017, 'Parent-teacher cooperation in the early childhood education: Directors' views to changes in the USA, Russia, and Finland', European Early Childhood Education Research Journal. https://doi.org/10.1080/135029 Early Childhood Edu
3X.2017.1356536

Vlasov, J., Hujala, E., Essary, J. \& Lenskaya, E., 2016, 'Longitudinal study of changes in teachers' views of early childhood education in the USA, Russia, and Finland' Journal of Early Childhood Education Research 5, 202-222. 